\title{
PROGRAMAS DE SUPLEMENTAÇÃO ALIMENTAR: IMPACTO SOBRE ALGUMAS VARIÁVEIS ECONÔMICAS
}

\author{
M.C.O. FURTUOSO \\ Departamento de Economia Doméstica-ESALQ/USP, C.P. 9, CEP: 13418-900-PIracicaba,SP
}

\begin{abstract}
RESUMO: Procurou-se avaliar quantitativamente as consequências de programas de suplementaçăo alimentar sobre o desempenho de algumas variáveis econômicas. Para tal, utilizamos um modelo de insumo-produto verificando o seu impacto sobre os níveis de produção, importaçāo e emprego. Trata-se de um exercício de símulaçāo de estática comparativa que analisa estados de equilibrio da economia sob hipóteses alternativas de consumo final. Duas alternativas de consumo, no setor indústria do leite e laticínios, correspondentes a hipotéticos gastos do governo no Programa Nacional do Leite para Crianças Carentes (PNLCC) foram testadas. Os resultados das simulaçós sugerem ser possível um estimulo ao setor estudado da ordem de $15 \%$, como também verificou-se impacto expressivo para geraçăo de emprego. Descritores: insumo-produto, programas de suplementaçăo alimentar
\end{abstract}

\section{FOOD SUPPLEMENTATION PROGRAMS: IMPACT ON SOME ECONOMICAL VARIABLES}

\begin{abstract}
The consequences of food supplementation programs on the performance of some economical variables was quantitatively evaluated. An input-output model was used and its impact on production, import, and employment levels ascertained. It is an exercise of comparative static simulation, analyzing the hypothetical balance states of economy under alternative hypotheses of final consumption. Two consumption alternatives, in the milk and dairy sectors, corresponding to hypothetical government expenses in the Mill National Program for Needy Children were tested. Simulation results suggested that the studied sector may be stimulated in $15 \%$ and a significant impact for job generation was also observed.
\end{abstract}

Key Words: input-output, food supplementation programs

\section{INTRODUÇĀO}

Os temas da desnutrição e da fome vem ressurgindo no Brasil com dramática intensidade nos últimos anos onde a situação de miséria e pobreza que atinge grande parcela da população brasileira constitui gravidade de amplo consenso nos diversos setores do país. Essa situação social é decorrente de uma iníqua distribuição das oportunidades e da riqueza, que fizeram com que o país vivesse uma das suas maiores contradições, ou seja, a $8^{\text {a }}$ economia do mundo, o $4^{\circ}$ maior exportador de grãos e ao mesmo tempo, o $6^{\circ} \mathrm{em}$ desnutrição, sendo o que apresenta a maior concentração de pobreza do Hemisfério Ocidental - a Região Nordeste (COUTINHO, 1988).

O quadro de distribuição de renda como reflexo do processo de crescimento excludente e concentrador, com persistência de acentuados níveis de pobreza, coloca-se como referencial das graves questões sociais vivenciadas pelo povo brasileiro. Os dados censitários - tomados a partir de 60 - mostram a tendência à concentração da renda: $o$ indice de Gini para 1960 era de 0,504 , passando para 0,561 em 1970; e em 1980, subindo para 0,592. Os dados sobre apropriação da renda gerada na economia revelam que os $50 \%$ mais pobres que em 1960 detinham $18,0 \%$ da renda, tiveram sua participação reduzida em 1980 para $13,8 \%$, enquanto os $10 \%$ mais ricos, que em 1960 , participaram de $40,5 \%$ da renda nacional aumentaram sua fatia para 49,6\% em 1980 .

HOFFMANN (1992), usando dados básicos das PNADs e do Censo Demográfico, apresenta a evolução dos rendimentos médios e dos indices de concentração de renda e pobreza entre famílias no período 1979-90. Pode-se constatar os efeitos da crise econômica em termos da queda de rendimentos e crescimento nos niveis de pobreza e o efêmero efeito do plano cruzado. Os indicadores de concentração de renda, que durante a primeira metade da década estavam praticamente estabilizados, se reduzem bruscamente em 1986 e em seguida apresentam um aumento contínuo até 1989 , que conforme menciona o autor aparentemente estão associados à aceleração da inflação observada no período. Em decorrência da estagnação da economia brasileira 
nessa década e da aceleração dos índices de concentração de renda observados, registra-se uma elevação nos índices de pobreza. Desta forma, enquanto em 1979, 20,8\% das familias brasileiras tinham rendimento inferior a 1 salário minimo, em 1990 essa proporção atinge $26,5 \%$.

Esses dados, de um modo geral, apontam para um quadro social desfavorável e sugerem o que pode estar ocorrendo com o estado nutricional das pessoas, uma vez que, inúmeras pesquisas têm indicado a renda como o principal determinante do nível nutricional das famílias estudadas (ALVES, 1977; MONTEIRO, 1988).

Segundo dados do Estudo Nacional de Despesa Familiar (ENDEF 1974/75), a insuficiência alimentar no Brasil é mais de ordem quantitativa que qualitativa, ou seja, o problema está ligado a um subconsumo de alimentos e não a uma seleção inadequada. Os resultados apresentados mostram ainda que, o déficit alimentar em 1975, atingia $67 \%$ da população. Considerando a crise econômica que se seguiu à realização desta pesquisa, pode-se inferir o que deve estar ocorrendo com o nível alimentar da população na atualidade.

Estas conclusões levam a uma modificação no enfoque da etiologia da desnutrição e, consequentemente, nas sóluções propostas, que deixam o âmbito de mudanças de hábitos alimentares para o de medidas, visando a melhor distribuiçăo de renda (ALVES, 1979).

A curto prazo, a tônica da ação governamental na área tem sido o atendimento aos grupos sociais carentes, através da ativação e expansão dos programas de distribuição de alimentos já existentes. Os críticos destes programas apontam para os seus custos elevados e seus defensores afirmam que além de auxiliar na redução do déficit alimentar provoca a consecução de uma produção de alimentos básicos e fomenta o emprego.

Assim, este trabalho tem como objetivo estudar o impacto de um programa de suplementação alimentar sobre o desempenho da economia, particularmente no que se refere às variaçðes na produção, na importação e no emprego.

\section{METODOLOGIA}

Utilizaremos, no presente estudo, um modelo pertencente à classe dos modelos de insumo-produto, no qual serão estabelecidos padrões de consumo final, para um dado setor especifico, diferentes dos que prevalecem no ano-base (1980) para verificar o seu impacto sobre os níveis de produção, im- portação e emprego, sendo estas mudanças comparadas com a estimativa inicial (original). Para tal, utilizamos um sistema térico fundamentado no trabalho de LEONTIEF (1966), no qual se leva em conta que o impacto de diferentes políticas governamentais afeta tanto os fluxos intersetoriais como a demanda de consumo. Tomamos como referêncial a literatura sobre análise de estruturas econômicas (PYATT \& ROE, 1977; HEWINGS, 1982) e o recente estudo sobre a evolução estrutural da economia brasileira (BAER et al., 1986).

Trata-se de um exercício de simulação de estática comparativa que analisa estados de equilibrio hipotéticos da economia sob hipóteses alternativas de consumo final. Como o modelo utilizado é do tipo insumo-produto, algumas de suas hipóteses básicas são as que se aplicam ao modelo estático de Leontief; outras săo específicas desta versão do modelo.

As hipóteses básicas são as seguintes:

a) o total de insumos utilizados na produção por cada setor é proporcional ao nível de produto daquele setor, sendo que a constante da proporcionalidade representa o coeficiente técnico de insumo-produto correspondente ao setor,

b) sendo os coeficientes técnicos fixos, não há possibilidade de substituição entre os fatores de produção;

c) o modelo admite rendimentos constantes de escala $\mathrm{e}$ as funções de produção dos diversos setores são lineares e homogêneas;

d) mudanças nos preços e salários não são consideradas;

e) a produção total de um bem é produzida pelas indústrias em proporções fixas;

f) os produtos vem de origem fixa.

Os dados utilizados foram obtidos basicamente da Matriz de insumo-produto para 1980 do Brasil, publicada pela FUNDAÇÃO INSTITUTO BRASILEIRO DE GEOGRAFIA E ESTATISTICA (1989), que doravante denominaremos "Matriz de 1980".

Como a "Matriz de 1980" foi elaborada para 88 setores produtivos e 137 produtos, foi realizado um trabalho de agregacão para 25 setores e 26 produtos. A agregaçăo dos setores obedeceu à classifi- 
cação das atividades a nivel de dois dígitos, segundo critérios estabelecidos pelo IBGE (TABELA 1).

A "Matriz de 1980" serviu ainda de fonte para a obtença dos valores dos componentes exógenos da demanda final (consumo pessoal, gastos do governo, formação bruta de capital fixo, variação de estoques e exportaç̃es) por setor. Para simplificação de nossa análise, as "dummy" reparação e de empresas, que aparecem desagregadas na "Matriz de 1980", foram incorporadas aos setores produtos diversos e outros serviços, respectivamente.

Os dados sobre emprego por setor (pessoal ocupado total do qual se subtraiu os trabalhadores sem remuneração foram obtidos, agregando-se a TABELA 12 da "Matriz de 1980" - Emprego e coeficientes de geração de emprego.

Utilizando o enfoque TECNOLOGIA BASEADA EM INDÚSTRIAS (LEONTIEF, 1951) Caso de Indústria por Produto, em sua formulação genérica, o modelo pode ser expresso por:

$$
\mathrm{X}=\mathrm{D} \cdot(\mathrm{I}-\mathrm{BD})^{-1} \cdot \mathrm{E}
$$

onde $\mathrm{X}$ é um vetor ( $\mathrm{n} \times 1)$ com o produto total de cada setor, $\mathrm{E}$ é um vetor $(\mathrm{m} \times 1)$ com a demanda final por produto, e D (I - BD) ${ }^{-1}$ é uma matriz ( $\mathrm{n} \times \mathrm{m}$ ) de coeficientes diretos e indiretos, de tecnologia baseada em indústria, relacionando indústria por produto, com os coeficientes técnicos de produção - $B(m$ $x$ n) (LEONTIEF, 1951). Neste modelo, o vetor de demandas finais é tratado como exógeno ao sistema, podendo ser divididas em demandas de consumo, gastos do governo, investimento (formação bruta de capital fixo - variação de estoques) e exportaçỡ:

$$
E=E^{c}+E^{b}+E^{i}+E^{e}
$$

O resultado da equação (1) nos fornece a solução para o ano de 1980, para as variáveis:

\section{- 25 valores de produção setoriais;}

- um valor de importações totais (importações para uso intermediário e importações diretas para consumo privado).

O resultado assim obtido é chamado de solução básica ou original. As outras soluç̃̃es são baseadas em duas simulaçб̃es alternativas que são comparadas com ela.

$O$ presente exercício considera duas alternativas diferentes de consumo pessoal (familiar), no setor indústria do leite e laticínios, correspondentes à hipotéticos gastos do governo em programas de suplementação alimentar - Programa Nacional de Leite para Crianças Carentes (PNLCC), os quais alterariam o consumo do leite das famílias. Os valores referentes a cada uma das duas alternativas são adicionados (acrescentados) no vetor $\mathrm{E}$, implicando diferentes resultados para as variáveis contidas no modelo.

O Programa Nacional do Leite para Crianças Carentes (PNLCC) pretendia atingir a meta para o ano de 1989 de distribuição de 1,3 bilhão de litros de leite a dez milhzes de crianças (UNIVERSIDADE ESTADUAL DE CAMPINAS, 1989). Se considerarmos que o preço médio no varejo do leite tipo C na cidade de São Paulo, em 1980, era de Cr\$16,04 (INSTITUTO DE ECONOMIA AGRfCOLA, 1990), teríamos o custo total do programa dispendido na compra do leite, no valor de aproximadamente $\mathrm{C}_{\mathbf{r}} \$$ 20 bilhões.

Partindo-se dessas informações, a respeito das metas do PNLCC, considerou-se a altemativa 1, simulando um acréscimo de $\mathrm{Cr} \$ 10$ bilhzes no vetor E, ou seja, $50 \%$ da meta pretendida pelo Programa de Ação Governamental - PAG; a alternativa 2 simula um acréscimo de Cr\$20 bilhões, ou seja, 100\% da meta estabelecida.

Obtidos os coeficientes de importação (volume de importação/volume de produção total), estes foram multiplicados pela variação total da produção total setorial, de modo a obter o impacto sobre a variável importação.

À partir do número do pessoal ocupado total (exclusive sem remuneração) nos diferentes setores foram obtidos os coeficientes de mão-de-obra (número de pessoas empregadas dividido pelo produto total, que serviram de base para calcular o impacto sobre o emprego.

Finalmente, calculou-se o Indice de Rasmussen (HEWINGS, 1982) como indicador dos efeitos de encadeamento de cada setor, como descrito pelas fórmulas (3) e (4),

$$
\begin{gathered}
T_{J}=\sum_{i=1}^{m} r_{y j} / m / \sum_{i=1}^{m} \sum_{j=1}^{m} r_{y j} / m^{2} \\
T_{i}=\sum_{i=1}^{m} r_{i j} / m / \sum_{i=1}^{m} \sum_{j=1}^{m} r_{t j} / m^{2}
\end{gathered}
$$

onde $\mathrm{r}_{\mathrm{y}}$ são os coeficientes da matriz (I - BD) ${ }^{-1}$; $m$ é o número de produtos;

$\sum_{i=1}^{m} r_{y} / m$ é a média dos coeficientes por coluna; $\sum_{i=1}^{m} \sum_{j=1}^{m} r_{i j} / m^{2} \quad$ é a média geral dos coeficientes; e valores de $T_{j}$ medem o grau de encadeamento (linkages) para trás desta indústria. 
TABELA 1 - Classificações de setores - Matriz $(25 \times 26)$

\begin{tabular}{ll}
\hline \hline 1. Agricultura & 14. Têxtil \\
2. Mineração & 15. Vestuário - Calçados e Couros \\
3. Mineração não-metálicos & 16. Outros produtos alimentares \\
4. Metalurgia & 17. Fumo \\
5. Mecânica & 18. Leite e Laticínios \\
6. Material elétrico & 19. Bebidas \\
7. Material de transporte & 20. Diversos \\
8. Madeira e Mobiliário & 21. Energia, Água e Saneamento \\
9. Papel - Papelão e Gráfica & 22. Construção Civil \\
10. Borracha & 23. Comércio \\
11. Química & 24. Transporte \\
12. Farmacêutica e Perfumaria & 25. Serviços \\
13. Plásticos & \\
\hline \hline
\end{tabular}

TABELA 2 - Efeitos de diferentes variações da demanda final na produção total (milhões de Cr\$ 1980).

\begin{tabular}{llrrr}
\hline \hline & Setores & \multicolumn{1}{c}{ Original } & Simulação 1 & Simulação 2 \\
\hline 1 & Agricultura & 1854672,22 & 1862539,28 & 1870406,34 \\
2 & Mineração & 147698,42 & 147721,78 & 147745,14 \\
3 & Mineração não metálicos & 514082,39 & 514196,41 & 514310,43 \\
4 & Metalurgia & 1300563,64 & 1301255,76 & 1301947,89 \\
5 & Mecânica & 644714,27 & 644910,07 & 645105,87 \\
6 & Material elétrico & 544214,04 & 544243,22 & 544272,39 \\
7 & Material de transporte & 447508,87 & 447517,82 & 447526,76 \\
8 & Madeira e Mobiliário & 352728,01 & 352755,54 & 352783,07 \\
9 & Papel, Papelão e Gráfica & 397688,73 & 397906,07 & 398123,41 \\
10 & Borracha & 126950,60 & 126980,21 & 127009,82 \\
11 & Química & 1647925,44 & 1649242,86 & 1650560,28 \\
12 & Farmacêutica e Perfumaria & 195178,23 & 195219,06 & 195259,89 \\
13 & Plásticos & 185677,73 & 185977,78 & 186277,82 \\
14 & Têxtil & 629439,13 & 629539,22 & 629639,32 \\
15 & Vestuário, Calçados e Couro & 445663,04 & 445675,71 & 445688,39 \\
16 & Outros produtos alimentares & 1543438,70 & 1544277,96 & 1545117,21 \\
17 & Fumo & 63344,36 & 63344,66 & 63344,95 \\
18 & Leite e Laticínios & 174529,40 & 188099,82 & 201670,24 \\
19 & Bebidas & 103157,11 & 103170,29 & 103183,46 \\
20 & Diversos & 242574,59 & 242666,00 & 242757,40 \\
21 & Energia, Água e Saneamento & 349474,04 & 349661,89 & 349849,74 \\
22 & Construção Civil & 2095377,01 & 2095428,43 & 2095479,85 \\
23 & Comércio & 1999551,93 & 2000256,07 & 2000960,21 \\
24 & Transporte & 993886,58 & 994175,90 & 994465,23 \\
25 & Serviços & 5674874,05 & 5676600,33 & 5678326,61 \\
T O T A L & 22674912,54 & 22703362,13 & 22731811,73 \\
\hline \hline
\end{tabular}

Fonte: Estimativas feitas pelo autor.

Simulação 1 e 2: Efeitos intersetoriais: equação 1. 
Por sua vez, que revelam, respectıvamente, $o$ indice de encadeamento para frente. Os valores de $T_{j}$ e $T_{1}$ podem ser usados para ordenar os setores segundo o grau de dinamismo de seus mercados intersetoriais.

\section{RESULTADOS E CONCLUSŌES}

O PNLCC visava a distribuição gratuíta de leite e seria implantado a partir de 1986. Entretanto, no período $1980-86$, a produção nacional de leite, indicador importante para a viabilização do progra$\mathrm{ma}$, vinha caindo e não conseguiu atingir o nível mínimo internacionalmente recomendado pela Food Administration Organ FAO - (1461/ano por pessoa) (13). As duas principais causas para explicar a reduzida disponibilidade da oferta de leite no mercado interno era uma política de preços desestimulante para o produtor e o baixo poder aquisitivo da população.

Dessa forma, pretende-se, também, verificar através das possibilidades de resposta da produção de leite a um aumento da demanda final do produto, via intervenção direta do setor público na economia, a viabilidade do Programa Nacional do Leite para Crianças Carentes (PNLCC).

As simulações empregadas para estudar os efeitos de variações da demanda final exógena (causada pelo setor público) na produção setorial, na utilização de insumos importados e na absorção de mãode-obra são as seguintes:

Simulação 1: Aumento de $\mathrm{Cr} \$ 10$ bilhôes na demanda final do produto leite referente ao setor 18 (leite e laticínios);

Simulação 2: Aumento de Cr\$ 20 bilhões na demanda final do produto leite referente ao setor 18 (leite e laticínios);

Estes aumentos correspondem, respectivamente, a 50 e $100 \%$ das metas originais estabelecidas pelo governo para o PNLCC.

Os resultados para os efeitos na produção setorial são apresentados na TABELA 2, os quais são obtidos da equação 1 .

Comparando-se os resultados para as diferentes simulações, nota-se que a importância relativa desses efeitos são diferentes, sendo mais expressivo para o setor 18 (Leite e Laticínios) 15,6\% e o setor 1 (Agricultura) $0,008 \%$. Os setores 4 (Metalurgia), 9 (Papel, Papelão e Gráfica), 11 (Química),
13 (Plásticos), 16 (Outros Produtos Alimentares) e 21 (Energia, Água e Saneamento) apresentam um efeito positivo, ainda que pequeno e os setores restantes, praticamente, não são impactados.

A primeira conclusão importante destas simulaçz̃es é o fato de que em uma economia caracterizada pela presença de distorções domésticas diversas, como é o caso do Brasil, medidas que visem aumentar o consumo de alimentos para a população de baixa renda podem levar ao estímulo da produção de alimentos.

Vale lembrar que é mais usual, numa economia de mercado, o estudo da estrutura de produção sob a ação de intervenções econômicas. Nesse contexto podemos apontar o trabalho de PELIANO (1985), que mostra a sensibilidade da agricultura às decisóes de política econômica. Na década de 70 as açōes governamentais favoreceram sistematicamente a agricultura dinâmica. Em contraste, a produção de alimentos básicos foi, na maioria dos casos, residual e desistimulante para o produtor.

Cumpre ressaltar que nos anos 80 o crescimento do setor agricola foi acompanhado de melhoria no desempenho da produção para o mercado interno, alterando o padrão viesado de crescimento à favor dos exportáveis verificado nos anos 70 , contrariando o receio de um agravamento do "problema de produção de alimentos".

A resposta da agricultura à crise dos anos 80 foi um excelente incremento de produtividade, um aumento na produção do segmento năo-exportável, com os termos de troca favorecendo à produção doméstica que passaram a liderar o crescimento agrícola. Há que se destacar o importante papel desempenhado pela política de preços mínimos como indutor do crescimento agrícola nessa década. Enfim, a agricultura brasileira mostrou seu potencial de mercado interno que pode ser acionado, também, por ações de âmbito social que além de apresentarem efeitos sobre a produção doméstica atacam frontalmente o problema nutricional brasileiro.

A TABELA 3 mostra os aumentos no uso de insumos importados resultantes de cada estratégia. Estes dados foram obtidos multiplicando-se um vetor com os coeficientes de insumos importados pela variação da produção total setorial. Os resultados mostram que o nível mais elevado de insumos importados corresponde ao setor 11 (Química) e o nivel mais reduzido corresponde ao setor 15 (Vestuário - calçados e couros). Embora menos sensiveis ao aumento da demanda final, os setores 18 (Leite e Laticínios) e 1 (Agricultura) também apresentam elevaçôes no 
TABELA 3 - Efeitos de diferentes simulaçø̋es nos insumos importados: variaçбes nos insumos importados (milhres de Crs 1980).

\begin{tabular}{|c|c|c|c|}
\hline & Setores & imulagão 1 & Simulağăo 2 \\
\hline 1 & Agricultura & 12,26 & 24,53 \\
\hline 2 & Mineração & 0,18 & 0,36 \\
\hline 3 & Mineração não metálicos & 1,08 & 2,17 \\
\hline 4 & Metalurgia & 35,46 & 70,92 \\
\hline 5 & Mecânica & 6,77 & 13,54 \\
\hline 6 & Material elétrico & 2,46 & 4,92 \\
\hline 7 & Material de transporte & 0,12 & 0,23 \\
\hline 8 & Madeira e Mobiliário & 0,15 & 0,30 \\
\hline 9 & Papel, Papelão e Gráfica & 5,54 & 11,08 \\
\hline 10 & Borracha & 1,91 & 3,82 \\
\hline 11 & Química & 492,21 & 984,42 \\
\hline 12 & Farmacêutica e Perfumaria & 3,64 & 7,27 \\
\hline 13 & Plásticos & 8,45 & 16,89 \\
\hline 14 & Têxtil & 0,67 & 1,34 \\
\hline 15 & Vestuário, Calçados e Couro & 0,05 & 0,11 \\
\hline 16 & Outros produtos alimentares & 43,87 & 87,74 \\
\hline 17 & Fumo & 0,39 & 0,79 \\
\hline 18 & Leite e Laticínios & 24,19 & 48,39 \\
\hline 19 & Bebidas & 0,66 & 1,33 \\
\hline 20 & Diversos & 10,15 & 20,29 \\
\hline 21 & Energia, Água e Saneamento & 0,69 & 1,37 \\
\hline 22 & Construção Civil & 0,69 & 1,38 \\
\hline 23 & Comércio & 5,47 & 10,93 \\
\hline 24 & Transporte & 32,85 & 65,71 \\
\hline 25 & Serviços & 23,32 & 46,64 \\
\hline
\end{tabular}

Fonte: Estimativas feitas pelo autor.

Obs: Os valores desta TABELA foram obtidos multiplicando-se o vetor com os coeficientes de insumos importados pela variação da produção total sensorial.

nivel absoluto das importações, sendo respectivamente, o $5^{\circ}$ e $7^{\circ}$ setores com maiores expansőes.

FONSECA \& GUILHOTO (1987), com o objetivo de estudar o impacto de diferentes estratégias governamentais sobre a produção setorial, a distribuição de rendas, a utilização de insumos importados e a absorção de mão-de-obra utilizou-se de uma metodologia baseado no trabalho de LEONTIEF \& MUJASAWA.

Os resultados indicaram que os impactos foram consideravelmente diferentes entre as três políticas públicas analisadas. No que se refere aos efeitos nos insumos importados pode-se observar que - nivel mais elevado correspondeu à estratégia de aumento no total de bens de capital demandados pelo governo e empresas públicas; o nivel mais reduzido correspondeu à estratégia de aumento no total de serviços providos pelo setor páblico. A situação intermediária coube ao setor de construçåo civil.
A TABELA 4 mostra o impacto setorial das diferentes simulaçбes sobre o emprego transmitidas por alteraçð̃es na estrutura de produção. Os resultados que encontramos nos permite concluir que o efeito de gastos governamentais através de mudanças do consumo final de um produto alimenticio é bastante expressivo para geração de emprego. As indústrias com maiores potencialidades, em nossas simulaçб̃es, para absorção de mão-de-obra são, por ordem de importância, a de Agricultura (1), Leite e Laticínios (18), Serviços (25), Comércio (23), Transporte (24) e outros produtos alimentares (16).

PELIANO (1985) analisando a gravidade da crise alimentar estimou ser o déficit global para o total da população desnutrida de $10,1 \times 10^{9} \mathrm{Kcal} / \mathrm{h}$ ano, o qual corresponde ao déficit médio de $322 \mathrm{cal}$ dia por pessoa. Para eliminar esse déficit, seria necessária a distribuiçăo anual de 2,9 milhros de toneladas de arroz, 968 mil toneladas de feijão, $587 \mathrm{mil}$ 
TABELA 4 - Efeitos de diferentes simulações de demanda final nos níveis de emprego setoriais da população brasileira.

\begin{tabular}{llrr}
\hline \hline Setores & Simulação 1 & Simulação 2 \\
1 & Agricultura & 24063,43 & 48126,87 \\
2 & Mineração & 19,39 & 38,79 \\
3 & Mineração não metálicos & 133,01 & 266,02 \\
4 & Metalurgia & 323,42 & 646,83 \\
5 & Mecânica & 169,69 & 339,38 \\
6 & Material elétrico & 15,96 & 31,91 \\
7 & Material de transporte & 4,52 & 9,04 \\
8 & Madeira e Mobiliário & 43,47 & 86,93 \\
9 & Papel, Papelão e Gráfica & 172,80 & 345,61 \\
10 & Borracha & 13,13 & 26,25 \\
11 & Química & 171,27 & 342,53 \\
12 & Farmacêutica e Perfumaria & 20,45 & 40,91 \\
13 & Plásticos & 208,42 & 416,83 \\
14 & Têxtil & 67,82 & 135,64 \\
15 & Vestuário, Calçados e Couro & 16,49 & 32,97 \\
16 & Outros produtos alimentares & 374,12 & 748,25 \\
17 & Fumo & 0,14 & 0,29 \\
18 & Leite e Laticínios & 3672,17 & 7344,35 \\
19 & Bebidas & 9,08 & 18,15 \\
20 & Diversos & 50,87 & 101,73 \\
21 & Energia, Água e Saneamento & 127,26 & 254,52 \\
22 & Construção Civil & 84,67 & 169,35 \\
23 & Comércio & 1123,62 & $\mathbf{2 2 4 7 , 2 3}$ \\
24 & Transporte & 442,06 & 654,12 \\
25 & Serviços & 3275,50 & 6550,99 \\
\hline
\end{tabular}

Fonte: Estimativas feitas pelo autor.

Obs: Estes dados foram obtidos multiplicando-se os coeficientes de mão-de-obra pela variação da produção total setorial.

toneladas de farinha de mandioca e 3,9 milhões de toneladas de leite pasteurizado. Tais quantitativos correspondem à aproximadamente $34 \%$ da média anual da produção de $1978 / 82$ de arroz, $42 \%$ da de feijão, $10 \%$ da de mandioca e $40 \%$ da de leite. Para se ter uma idéia do efeito sobre o emprego de uma maior produçáo de alimentos, caso se aumentasse a produção destes produtos nos volumes citados, seriam gerados diretamente o equivalente a 330 mil novos empregos permanentes na agricultura.

Assim, percebe-se que os programas de distribuição gratuita, particularmente para os contingentes populacionais que se situam na base da pirâmide social, atende a uma necessidade premente devido à dimensão da população subnutrida, de forma a garantir o acesso a gêneros essenciais na alimentação e provoca um efeito multiplicador sobre o emprego do campo e nas cidades.
Dado o impacto setorial de cada simulação, conforme discutido, pode-se notar, com base na TABELA 5 , que a absorção de mão-de-obra é maior no setor 1 (Agricultura).

A TABELA 6 apresenta 0 indice de Rasmussen $\left(T_{j} \in T_{j}\right)$, respectivamente. Ao examinar as estimativas obtidas observa-se que, embora o conceito de poder de encadeamento (linkages) seja usado frequentemente para justificar o fomento aos setores indutriais moderno, os cálculos do presente trabalho mostram que estas atividades não são necessariamente aquelas com os maiores índices de encadeamento para trás $\left(T_{j}\right)$. Com relação aos efeitos para frente $\left(T_{i}\right)$, é esperado que setores industriais modernos como Metalurgia $(2,013)$, Química $(2,575)$ - Mecânica $(1,039)$ desempenhem papéis cruciais como fornecedores de insumos da economia brasileira. Entretanto, os índices de encadeamento para 
TABELA 5 - Coeficientes de mão-de-obra: número de pessoas ocupadas divididas pelo produto total.

\begin{tabular}{|c|c|c|c|c|c|}
\hline & Setores & ficientes & & Setores & eficientes \\
\hline 1 & Agricultura & 3,059 & 14 & Têxtil & 0,678 \\
\hline 2 & Mineracão & 0,830 & 15 & Vestuário, Calcados e Couro & 1,301 \\
\hline 3 & Mineração não metálicos & 1,167 & 16 & Outros produtos alimentares & 0,446 \\
\hline 4 & Metalurgia & 0,467 & 17 & Fumo & 0,483 \\
\hline 5 & Mecânica & 0,867 & 18 & Leite e Laticínios & 0,271 \\
\hline 6 & Material elétrico & 0,547 & 19 & Bebidas & 0,689 \\
\hline 7 & Material de transporte & 0,505 & 20 & Diversos & 0,557 \\
\hline 8 & Madeira e Mobiliário & 1,579 & 21 & Energia, Água e Saneamento & 0,677 \\
\hline 9 & Papel, Papelão e Gráfica & 0,795 & 22 & Construção Civil & 1,647 \\
\hline 10 & Borracha & 0,443 & 23 & Comércio & 1,596 \\
\hline 11 & Química & 0,130 & 24 & Transporte & 1,528 \\
\hline 12 & Farmacêutica e Perfumaria & 0,501 & 25 & Serviços & 1,897 \\
\hline 13 & Plásticos & 0,695 & & & \\
\hline
\end{tabular}

Fonte: Estimativas feitas pelo autor.

TABELA 6 - Indice de Rasmussen: efeitos de encadeamento setorial para trás (T, e para frente (T,).

\begin{tabular}{llll}
\hline \hline Setores & Índice $T_{1}$ & Índice $T_{1}$ \\
\hline 1 & Agricultura & 0,821 & 2,142 \\
2 & Mineração & 0,811 & 0,585 \\
3 & Mineração não metálicos & 0,926 & 0,908 \\
4 & Metalurgia & 1,239 & 2,013 \\
5 & Mecânịca & 1,037 & 1,039 \\
6 & Material elétrico & 1,002 & 0,674 \\
7 & Material de transporte & 0,954 & 0,490 \\
8 & Madeira e Mobiliário & 1,042 & 0,685 \\
9 & Papel, Papelão e Gráfica & 1,015 & 0,958 \\
10 & Borracha & 1,151 & 0,774 \\
11 & Química & 0,807 & 2,575 \\
12 & Farmacêutica e Perfumaria & 0,933 & 0,533 \\
13 & Plásticos & 0,990 & 0,708 \\
14 & Téxtil & 1,183 & 1,255 \\
15 & Vestuário, Calçados e Couro & 1,137 & 0,529 \\
16 & Outros produtos alimentares & 1,188 & 0,964 \\
17 & Fumo & 1,010 & 0,595 \\
18 & Leite e Laticínios & 1,376 & 0,778 \\
19 & Bebidas & 1,233 & 0,505 \\
20 & Diversos & 1,079 & 0,536 \\
21 & Energia, Água e Saneamento & 0,955 & 0,803 \\
22 & Construção Civil & 0,865 & 0,911 \\
23 & Comércio & 0,995 & 0,596 \\
24 & Transporte & 0,742 & 0,994 \\
25 & Serviços & 0,745 & 2,516 \\
\hline
\end{tabular}


frente de setores não-industriais como Agricultura $(2,142)$ e Serviços $(2,516)$, são bastante elevados também. É importante salientar que os resultados obtidos nesse estudo sobre os efeitos de encadeamento não permitem comparações com as estimativas de outros autores por se tratar de enfoque diferente usado para os cálculos.

As conclusões a que esse estudo permite chegar, especificamente com respeito à viabilidade do Programa Nacional do Leite para Crianças Carentes (PNLCC) é ser possivel um estímulo ao setor de Leite e Laticínios da ordem de $15 \%$, via gastos governamentais.

No entanto, esse valor se refere não a produção de leite, mas a produção total do setor.

Assim, para suprir um programa nos moldes do PNLCC, que previa ampla distribuiçăo de leite fluído, seria necessário também a adoção de medidas paralelas de curto e longo prazos para estimular a produção diretamente do produto.

Com todo o cuidado que se deve ter na interpretação dos resultados, tendo em vista as hipóteses restritivas nas quais o modelo se baseia, são estas as principais conclusões a que chegamos na análise dos efeitos de políticas de suplementação alimentar sobre o funcionamento da economia brasileira.

\section{REFERÊNCIAS BIBLIOGRÁFICAS}

ALVES, E.L.G. Desnutrição e pobreza no Brasil: algumas evidências. Cadernos de Pesquisa, São Paulo, v.29, p.77$86,1979$.

ALVES, E.L.G. Nivel alimentar, renda e educação. Revista ABLA/SAPRO, São Paulo, v.30, p.17-44, 1977.

BAER, W.; GUILHOTO, J.J.M.; FONSECA, M.A.R. da. Mudanças estruturais na economia industrial brasileira: 1960-1980. Conjuntura Econômica, Rio de Janeiro, v.40, n.7, p.95-103, 1986.

COUTINHO, A.O.N. Alimentação do brasileiro: uma visão histórica. Saúde em Debate, São Paulo, p.12-21, dez. 1988.

FONSECA, M.A.R. da; GUILHOTO, J.J.M. Uma análise dos efeitos econômicos de estratégias setoriais. Revista Brasileira de Economin, Rio de Janeiro, v.41, n.1, p.81$98,1987$.
FUNDAÇÃO INSTITUTO BRASILEIRO DE GEOGRAFIA E ESTATÍSTICA Estatísticas históricas do Brasil. Rio de Janeiro, 1990. 642p. (Séries Econômicas Demográficas e Sociais de 1950-1988).

FUNDAÇÃO INSTITUTG BRASILEIRO DE GEOGRAFIA E ESTATÍSTICA. Estudo nacional da despesa famillar. Rio de Janeiro, 1977-1978. 3v.

FUNDAÇÃO INSTITUTO BRASILEIRO DE GEOGRAFIA E ESTATISTICA Matriz de insumo - produto Brasil - 1980. Rio de Janeiro, 1989. (Série Relatórios Metodológicos, 7).

HEWINGS, G.J.D. Trade, structure and linkages in developing and regional economics. Journal of Development Economics, Amsterdam, v.11, p.91-96, 1982.

HOFFMANN, R. Crise econômica e pobreza no Brasil no perfodo 1979-90. Piracicaba: ESALQ, 1992. 49p.

INSTITUTO DE ECONOMIA AGRÍCOLA Estatísticas de preços agrícolas no.Estado de São Paulo. 2.ed. São Paulo, 1990. 3v.

LEONTIEF, W.W. The structure of the american economy. 2.ed., New York: Oxford University Press, 1951. 264p.

MONTEIRO, C.A. Saúde e nutriçāo das crianças de São Paulo: diagnóstico, contrastes sociais e tendências. São Paulo: HICITEC/EDUSP, 1988. 165p.

PELIANO, A.M.M. O problema alimentar brasileiro: situação atual, perspectivas e proposta de politicas. In: CASTRO, C.M.de S.; COIMBRA, M. O problema alimentar no Brasill. São Paulo: ALMED, 1985.

PYATT, G.; ROE, A. Social accounting for development planning. Cambridge: Cambridge University Press, 1977.

UNIVERSIDADE ESTADUAL DE CAMPINAS. NÚCLEO DE ESTUDOS DE POLITICAS PUBLICAS. Brasil 1987: relatório sobre a situaçào social do país. Campinas, 1989, $541 \mathrm{p}$.

Recebido para publicação em 24.10 .94

Aceito para publicaçào em 14.11.95 